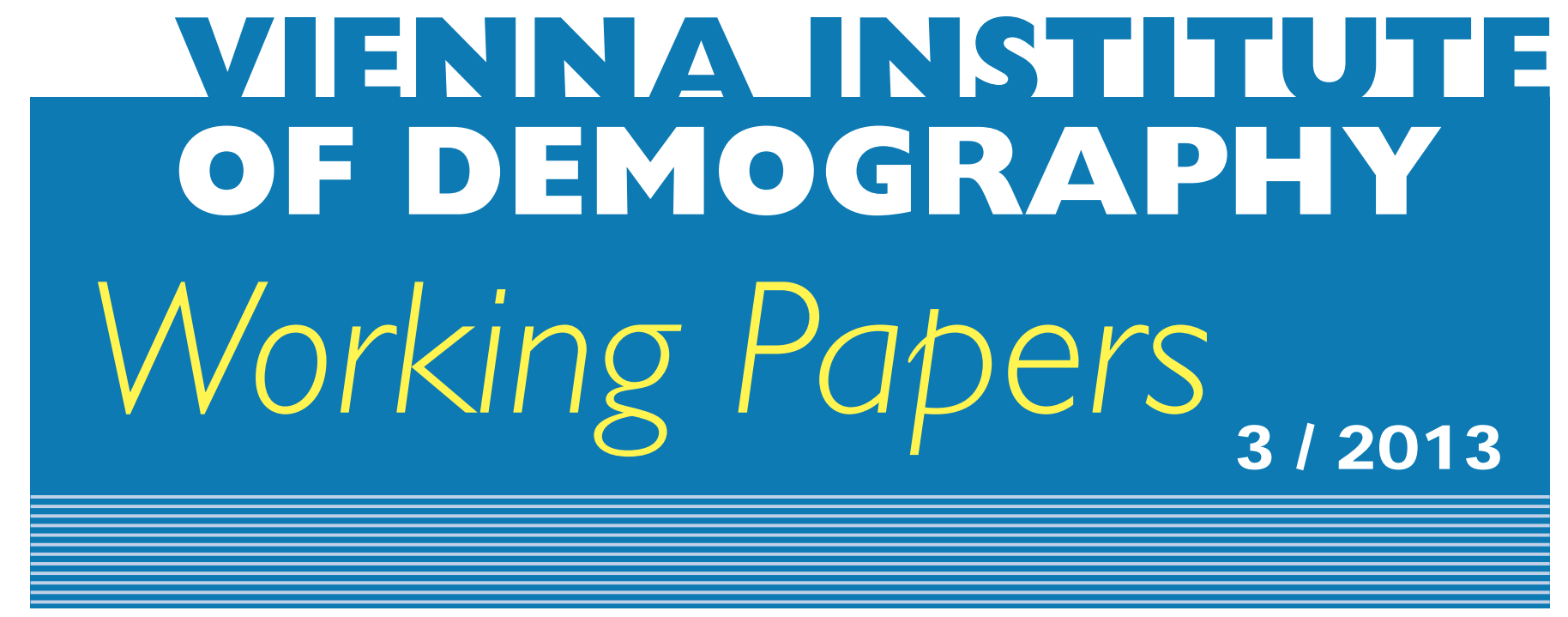

M aria W inkler-Dworak and Heiner Kaden

\title{
The Longevity of Academicians: Evidence from the Saxonian Academy of Sciences and $H$ umanities in Leipzig
}

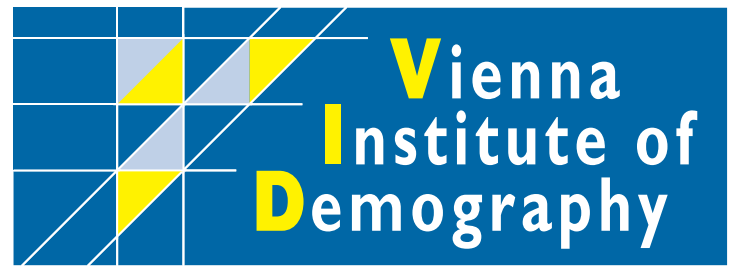

Vienna Institute of Demography Austrian Academy of Sciences

Wohllebengasse 12-14

A-I040Vienna $\cdot$ Austria

E-Mail:vid@oeaw.ac.at

Website: www.oeaw.ac.at/vid

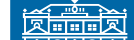

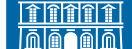

CA

Austrian Academy of Sciences 


\begin{abstract}
This study addresses the mortality of the members of the Saxonian Academy of Sciences and Humanities in Leipzig. In fact, learned societies have been shown to present vanguard groups in the achievement of longevity. We use biographical records from the members of the Saxonian Academy of Sciences from 1846 to 2010 and compare their mortality to German life table estimates, where particularly attention is paid to the mortality differentials between eastern and western Germany. The Saxonian academicians show indeed a higher life expectancy at age 60 than the general German male population, where the gap has been widening since the 1950s. Comparing the life expectancy values for the Saxonian academicians to available estimates of various European learned societies yields a similar longevity, suggesting that the survival of the academicians is less determined by national mortality conditions but that academicians rather share a common health advantage.
\end{abstract}

\title{
Keywords
}

Longevity, Academies of Sciences, Germany

\section{Authors}

Maria Winkler-Dworak (corresponding author), Wittgenstein Centre for Demography and Global Human Capital (IIASA, VID/ÖAW, WU), Vienna Institute of Demography/Austrian Academy of Sciences. Email: Maria.Winkler-Dworak@oeaw.ac.at

Heiner Kaden, Meinsberg Research Institute of Measuring and Sensor Technology, Full member of the Saxonian Academy of Sciences and Humanities.

\section{Acknowledgements}

We appreciate the financial support from the Austrian Science Foundation (FWF) under contract no. P20408-G14 ("Age Structured Populations with Fixed Size"). Moreover, we are grateful to Christian Wegner for helpful advices and comments and to Marc Luy for providing us data on life expectancy in Germany from 1950 to 2010. 


\title{
The Longevity of Academicians: Evidence from the Saxonian Academy of Sciences and Humanities in Leipzig
}

\author{
Maria Winkler-Dworak and Heiner Kaden
}

\section{Introduction}

Members of academies of sciences have been shown to exhibit a remarkably high life expectancy and are being considered as vanguard groups in the achievement of longevity (e.g., Andreev et al. 2011; Winkler-Dworak 2008). Following the social gradient of mortality, members of learned societies should indeed show much lower death rates than most other social groups. As scientific elites, they not only surpass the highest educational levels, they also occupy (or have retired from) prestigious positions usually associated with high income. Moreover, election into a learned society signifies an "outstanding contribution to science and confers an elevated status with, and to some extent, outside the scientific community" (Andreev et al. 2011, p. 319).

In this paper, we investigate the mortality of the members of the Saxonian Academy of Sciences and Humanities in Leipzig, which was founded in 1846, to the present. There are several ways how studying the longevity of members of an academy of sciences over such a long period of time may improve the understanding of longevity. First, the life expectancy of such population groups living in favourable conditions may indicate upper bounds of longevity to which national populations may aspire given current knowledge and medical technology (Andreev et al. 2011), thus contributing to the debate about any further extending potential of life expectancy in general (Martelin 1996; Manton et al. 1991; Olshansky et al. 1990). Furthermore, the analysis of mortality of such privileged groups may not only yield an approximation to the potential maximum life expectancy in each historical epoch (Andreev et al. 2011) but could also provide insights into social differences in mortality when combined with estimates for other social groups or national populations at the time. In addition, such a comparison may be used to construct hypotheses about causes of specific diseases and changes in mortality over time (Martelin 1996).

The mortality of members of a learned society has attracted the attention of demographers before. Houdaille (1980) studied the mortality of several leading groups in France in the 18th and 19th century, and he noted that French academicians exhibited a remarkably low mortality in comparison with their contemporaries. More recently, Leridon (2004) investigated the demography of the members of the French Academy of Sciences and he found that mortality differentials still persist (Leridon 2005). Furthermore, Matthiessen (1998) studied the demographic development of the Royal Danish Academy of Sciences and Letters, just as van de Kaa and de Roo (2008) analysed the Royal Netherlands Academy of Arts and Sciences. They also identified a considerably lower mortality for academicians in comparison to the corresponding national population. Winkler-Dworak (2008) revealed that the members of the Austrian Academy of Sciences show an even lower mortality than the Austrian population with tertiary education. In 
analysing the longevity of members of the Royal Society and the Russian Academy of Sciences, Andreev et al. (2011, p. 328) concluded that "over the past few decades [life expectancy] at age 50 of the [Royal Society], and more recently of the [Russian Academy of Sciences], exceeded that of any national population in the world." Moreover, the trend of the life expectancy of the Russian academy members sharply contrasts that of the Russian population over the past decades, i.e., Russian academicians did not experience the mortality crisis observed in Russia since the 1990s, during a time with political changes and where economic crises hit Russia (Shkolnikov et al. 1998).

Saxony as a part of former East Germany also underwent several political, societal and economic changes in history, which have not been without consequences in the development of its demographic parameters. Prior to 1945, eastern and western Germany had an almost identical and demographic composition and behaviour, which was then followed by 45 years under different political and socioeconomic structures resulting in entirely different demographic developments (Gjonça et al. 2000). In the case of mortality, life expectancy of East German men rose at a slower pace than for West German men resulting in a widening gap of life expectancy. It was the Reunification in 1990, where "the population in Eastern Germany returned to the Western societal and economic system that caused sudden changes in the development of all its demographic parameters" (Luy 2004, p. 99). In particular, a striking decrease in life expectancy among eastern German men was observed in 1990, coinciding with the Reunification and the ensuing changes, at first called a 'demographic shock' (Eberstadt 1994) or the eastern German 'mortality crisis' (Riphahn 1999; Nolte et al. 2000). However, the long-term trend was a rapid closing of the gap, which has almost vanished nowadays (Luy 2004; Kibele and Scholz 2009).

Given the historic political, societal, and economic changes, we might ask whether the Saxonian academicians were insulated from stagnating or negative developments in mortality just like the Russian academicians, and more recently, whether they have benefited from improved survival conditions even more than the general East German population. Does the trend in mortality of the Saxonian academicians parallel that of the general population or does the survival of the Saxonian academicians rather resemble that of other European academicians and is less influenced by national conditions?

This article is structured as follows. Section 2 presents the reconstruction of the data from biographical records of the members of the Saxonian Academy of Sciences and the statistical methods used. In Section 3 the results of the mortality analysis over time are shown. Moreover, comparisons to the general population as well as to previously published estimates of the life expectancy of other European academies of sciences are drawn. Finally, Section 4 discusses the results and concludes.

\section{Data and Methods}

\subsection{Reconstruction from Biographical Records}

The data come from biographical records of the members of the Saxonian Academy of Sciences (SAW) from 1846 to 2010. Wiemers and Fischer (2006) collected membership 
information for all members up to 2006, including field of work, date of election, date and place of birth, and if applicable, date and place of death and changes in membership status. We updated the membership records for 2006-2010 using almanacs of the SAW for 20052006 (Schlegel 2007), 2007-2008, and 2009-2010, (Kaden 2009; 2011). The SAW was founded in 1846 and structured around two sections - the Mathematical-Natural Sciences Class and the Philological-Historical Class. In 1996 a further section was added, the Class of Engineering Sciences. Membership distinguishes nowadays between full members, corresponding members and honorary members, while in the past (full) membership was (further) distinguished between resident and non-resident in Saxony and corresponding membership was only introduced by 1928. Moreover, in 1884 the bye-laws allowed to elect also extraordinary members with fewer rights (no voting rights) though this status was restricted to residence in Saxony only, i.e. in contrast to the full members, extraordinary members, when moving outside Saxony, lost their membership rather than changing to the group of non-resident members. Eventually, the status of extraordinary members ceased to exist in $1940 .{ }^{1}$ Honorary members have been predominately sovereigns and ministers of education, and therefore, we ignore honorary members in this study and only focus on the remaining scientific membership categories. ${ }^{2}$

It was after 1945 when there was a peculiar change in the membership as about forty members transferred their place of work and residence from East to West Germany, for personal or ideological reasons. Partially, the move of these Leipzig professors and their families was enforced by the American occupying forces. We investigate the survival of these academicians in comparison to those members who remained in East Germany, as differences in life expectancy have been observed for the general population of East and West Germany after 1945.

The period of observation for the Saxonian Academy of Sciences extends from its foundation in 1846 to 31 December 2010. At the end of the observation period, there was a total of 830 members, of which 21 were females. Hence, due to the low number of females, we perform the subsequent mortality analysis for male members only, of which 573 had died by the end of 2010. Membership is usually lifelong, though for twenty members an end of membership other than by death has been registered (e.g., extraordinary members moving out of Saxony). For seven among them, a date of re-election to the academy has been documented.

Academies carefully maintain their membership registers, so the data quality of the biographical information on the academicians is excellent. In 13 records (1.6 per cent), the exact date of an event was unknown, so we set it by the middle of the given month or year, respectively.

\footnotetext{
${ }^{1}$ For more details on the different membership categories and their changes over time see Wiemers and Fischer (2006).

2 Honorary member Prof. Gadamer got elected first as full member and then changed his status to corresponding member when moving to Heidelberg and eventually got elected in 1996 as an honorary member. Since he entered the academy as a scientific member, we kept his biographic information in the mortality analysis.
} 


\subsection{Statistical Methods}

For analysing the longevity of the academicians we constructed a survival dataset from the biographical records of the academy members, i.e. we followed the individuals from the date of election to any scientific membership category to their date of death or to 31 December 2010, i.e. the end of the observation period, whichever occurred first. In addition we took care of right- and left censoring due to premature exit and re-election, if applicable. As illustrated by Figure 1, election into the SAW takes place usually in the middle ages of adult life, with an average tenure of around 20-25 years (Kaden et al. forthcoming, also to be consulted for further details of the member population of SAW).

For a mortality comparison between different groups of members, we applied the log-rank test in order to test for the equality of the survival curves. In order to describe mortality differentials between the academicians and the total population, the life expectancy of academicians for various periods was estimated. Therefore, we aggregated the individual exposure into combinations of age groups and calendar year periods, where we had to employ 30-year and 10-year periods, respectively, due to low numbers. Table 1 summarises the survival data by periods used in the analysis.

Figure 1: Box plot of age distribution at election of male members of the Saxonian Academy of Sciences for 10-year periods, 1846-2010. The boxes denote the interquartile range and the solid line within the boxes denotes the median of the age at election. The whiskers give the lower and upper adjacent values as defined by Tukey (1977), while the crosses represent outliers.

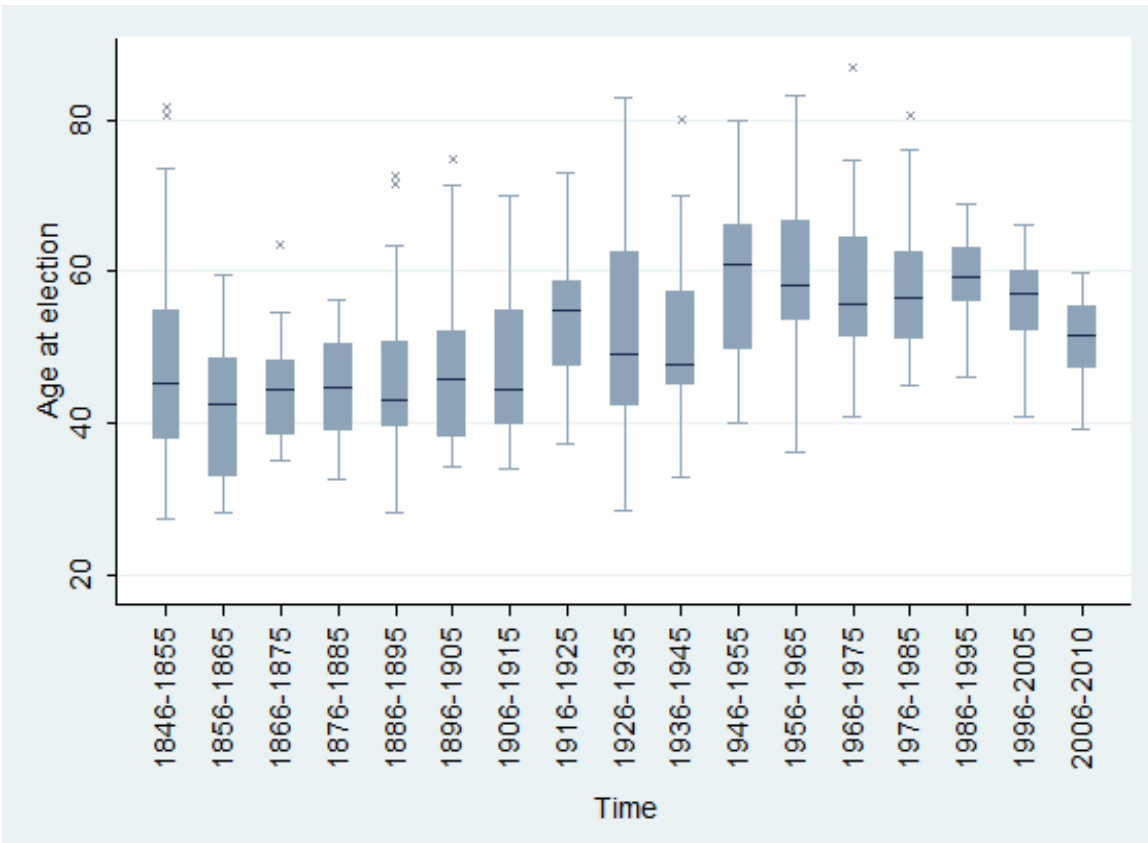


Table 1: Person-years and number of deaths by calendar period for members of the Saxonian Academy of Sciences, 1846-2010.

\begin{tabular}{rrr}
\hline Calendar period & Person-years & Deaths \\
\hline $1846-1875$ & 1426.3 & 41 \\
$1876-1905$ & 2074.6 & 81 \\
$1906-1935$ & 2373.1 & 101 \\
$1936-1965$ & 3247.6 & 128 \\
$1966-1975$ & 1230.2 & 59 \\
$1976-1986$ & 1243.5 & 55 \\
$1986-1995$ & 1317.5 & 57 \\
$1996-2005$ & 1735.1 & 32 \\
$2006-2010$ & 1008.4 & 19 \\
\hline
\end{tabular}

Relating period- and age-specific person-years at risk to corresponding death counts yielded period- and age-specific death rates. By assuming an exponential model, the latter were converted into probabilities and abridged period life tables were estimated for the academicians. In order to evaluate the influence of outstanding academicians regarding their mortality on the results of the survival analysis, we applied bootstrapping for the derivation of $95 \%$ confidence intervals. We present life expectancy estimates for age 60 for the academicians as at this age the majority of members have been elected to the academy for all periods except for around the mid-20th century (see Figure 1). Due to the advanced age at election, the survival analysis may suffer from selection Therefore, we conducted a sensitivity analysis similar to Andreev et al. (2011), where we re-estimated life expectancy at age 60 after exclusion of deaths and exposure time for the first 2, 5 and 8 years after election, thus producing an even more selected sample of academicians with respect to age. The resulting differences in the life expectancy at age 60 were only minor (on average up to half a year in absolute terms). Moreover, we decompose differences in life expectancy between academicians and the general populations by age following the method by Andreev et al. (2002). The analyses were performed using STATA 11 (StataCorp 2009).

\section{Results}

The upper graph of Figure 2 presents the life expectancy at age 60 for academy members obtained from overlapping abridged period life tables for 30 year periods shown for the central year of the period. In the first decades of its existence, the life expectancy at age 60 for the members of the SAW amounted to 13.9 years. For the 30 -year periods around the 1860s, the graph exhibits a small hump, though its statistical significance is unclear, as indicated by the wide confidence intervals. In the late 19th century, life expectancy at age 60 of academicians remained quite stable around 13-14 years. Then in early 20th century, the estimated life expectancy values at age 60 started to increase, surpassing 17 years in 1943-72 and by 1963-1992 even 19 years. In the most recent decades, the pace of increase in life expectancy at age 60 further accelerated, reaching 23.5 years for the most recent 30year period, 1981-2010. 
For the recent decades, the SAW membership size even permitted to investigate shorter periods in order to observe the latest trends in life expectancy more closely. The lower panel of Figure 2 displays life expectancy at age 60 for academy members for overlapping 10-year periods. The steep increase of life expectancy is also evident here, the average gain corresponding to 4.5 months per year! For the latest decade, 2001-2010, the SAW members may even expect 27.8 years of further life at age 60 according to our estimates.

Figure 2: Remaining life expectancy at age 60 of male academicians for overlapping 30year (upper panel) and 10-year periods (lower panel) centred around the middle of the period in comparison to (annual) life table estimates for German males, 1846-2010.
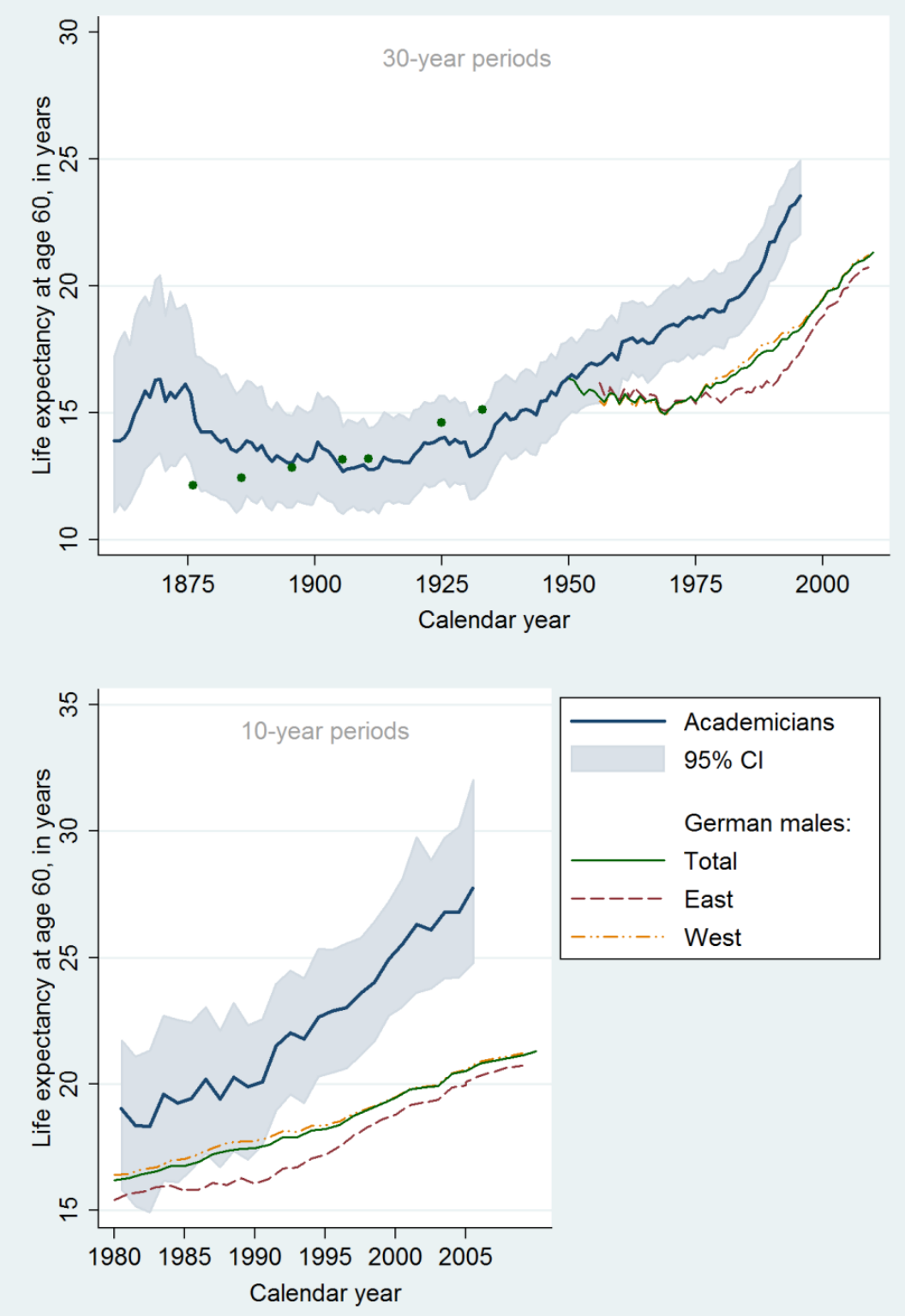

Source: Authors' own calculations, Human Life-Table Database, Human Mortality Database, Lebenserwartung.info. 
Figure 2 also compares the longevity of the academicians to life table estimates for the male German population, total and separately for East and West Germany after 1956. In the 19th century, life expectancy at age 60 for the SAW lies slightly above the corresponding values for the German male population (with a difference of about 0.4 to 3.5 years) but the national estimates are still within the 95 per cent confidence bands. The few life table estimates available for the German population for the first half of the 20th century are very close to those obtained for 30-year periods for the SAW members.

Starting from the 1950s onwards, annual life table estimates for Germany are available from the Human Mortality Database and Lebenserwartung.info. Life expectancy at age 60 for the male German population amounted to 16.3 in 1950, which is very close to the estimates for the academicians around that time. However, life expectancy at age 60 for German men exhibits a slight downward trend over the 1950s and 1960s. The mortality increase during this period has been ascribed on the one hand to consequences of the world wars, i.e. negative risk selection of the population due to military losses (Haudidier 1996) and the poor alimentary situation of the population right after the war (Horiuchi 1983), as well as to serious influenza epidemics (Luy 2004; Meyer and Rückert 1975). By contrast, the academicians were insulated from these negative developments, with the life expectancy at age 60 for the SAW members increasing continuously and even significantly above the corresponding values for the male German population. By the 1960s at the latest, death rates at all ages declined for German men resulting in a general increase of life expectancy in Germany, as well.

By the mid-1970s, the survival conditions in East and West Germany started to diverge, with life expectancy rising more steeply in West than in East Germany. The life expectancy values at age 60 of the male population in both countries, however, are surpassed by the corresponding estimates for the SAW members. Moreover, the increase of the latter over time is even more pronounced, resulting in a widening gap not only between East and West Germany but also between the academicians and the male populations of both East and West Germany.

Around Reunification in 1990, there was a sudden increase in mortality among East German men. However, this short peak in mortality was limited to ages 15-65 (Dorbritz and Gärtner 1995), and thus, hardly visible in Figure 2. After this temporary setback, life expectancy for eastern German males rapidly increased again, implying a narrowing of the gap between eastern and western Germany to 1.4 years at age 60 in 2010. Nonetheless, SAW members exhibit an even stronger increase in life expectancy at age 60 , and thus the gap in survival between the academicians and the male population widens further. The latter is also visible from Table 2 which decomposes the academicians-population difference in life expectancy at age 60 into the contributions by broad age groups.

In the decade before Reunification, the age groups above age 70 predominately contributed to the difference in life expectancy between SAW members and East German men, while after Reunification, the shares shifted to the ages below 70. The latter result corresponds to the accelerated decline in death rates observed for ages above 70 in eastern Germany in the 1990s, which has been ascribed to rapid improvements in the availability of medical and nursing care (Gjonça et al. 2000; Luy 2004). In the following decade, the 
contributions to the life expectancy differences between academicians and the male German population are more evenly spread across age groups. In other words, the academicians benefit more at every age from improvements in survival compared to the general male population.

Table 2: Decomposition of difference in life expectancy at age 60 (LE) between SAW members and general population, by age group and most recent 10 -year periods.

\begin{tabular}{llrrr}
\hline & LE difference & \multicolumn{3}{c}{ Contribution of age group } \\
\cline { 3 - 5 } Period & SAW - total population & $60-69$ & $70-79$ & $80+$ \\
\hline \multirow{2}{*}{$1980-1989$} & East/eastern Germany & & & \\
$1990-1999$ & $5.4(0.3,6.7)$ & $0.6(-1.8,2.5)$ & $1.7(0.2,2.9)$ & $1.1(0.3,2.7)$ \\
$2000-2009$ & $6.9(4.3,10.2)$ & $3.1(1.8,3.7)$ & $1.8(0.0,3.1)$ & $0.6(-0.3,2.0)$ \\
& Total Germany & $2.3(0.6,3.1)$ & $2.8(1.7,3.7)$ & $1.8(0.4,4.7)$ \\
$1990-1999$ & $4.4(2.1,7.1)$ & & & \\
$2000-2009$ & $6.5(3.9,9.8)$ & $2.6(1.2,3.3)$ & $1.4(-0.4,2.8)$ & $0.5(-0.5,1.9)$ \\
\hline
\end{tabular}

Note: 95 per cent confidence in brackets.

Source: Authors' own calculations; 10-year period life tables for general German male population from Human Mortality Database.

Finally, we compare the mortality between SAW members who transferred for personal or ideological reasons their place of work and residence from East to West Germany after 1945 and those who remained in East Germany. In particular, we investigate the survival of 103 full members born in 1875-1911, 42 of whom migrated to the West. In fact, the full members staying in East Germany exhibited a lower mean age at death of about 2.8 years in comparison to their peers who had moved to the West $(\mathrm{p}=0.08)$.

As the emigration of members to the West also involved a change in their membership status, we were able to reconstruct their place of residence during their membership. Figure 3 compares the Kaplan-Meier survivor functions of those members by place of residence. The impressively low mortality of the academicians is also evident here: almost one-half of the full members surpassed age 80 even at that time (41.1 per cent of those remaining in the East and 49.8 per cent for those emigrating to the West, respectively).

While there are no visible differences between the survivor functions below age 80, Figure 3 reveals minor differences by place of residence beyond that age. This observation is consistent with the differences in old-age mortality between East and West Germany before 1990 (Kibele and Scholz 2009). It is well documented that the availability or lack of appropriate medical and nursing care is crucial for old-age mortality. Therefore, differences in the welfare system have been used to explain differences in old-age mortality between East and West Germany prior to Reunification. In particular, while the West German welfare system, characterised as status-preserving and transfer-oriented, disproportionately favoured the elderly, the East German welfare regime focused on the young and middle-aged population (Gjonça et al. 2000). However, the log rank test does 
not report the survivor curves by place of residence in East and West, respectively, to be different with any statistical significance.

Figure 3: Kaplan-Meier survivor function for full members by place of residence, birth cohorts $1875-1911$.

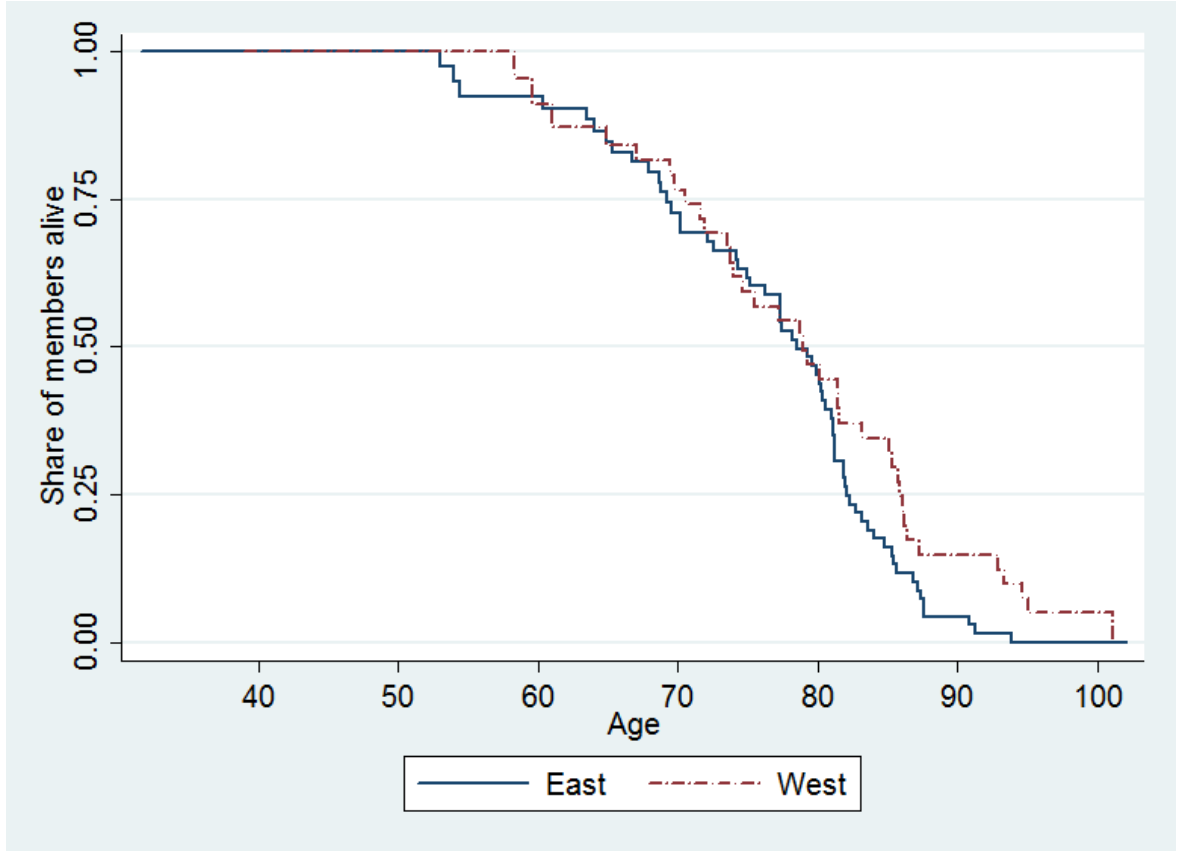

\section{Discussion}

The members of the Saxonian Academy of Sciences indeed exhibit a remarkable longevity: the academicians have a life expectancy at age 60, which is almost 7 years above the corresponding value for the male German population in the most recent period, 20002010. Given the steep increase in the life expectancy of the academicians during the past decades, this finding suggests a remarkable potential of further extending longevity for the German population. In other words, the German population could aspire to a substantial increase in survival to high ages.

However, the survival advantage has varied over time. While the gap in life expectancy was widening in the past six decades, it was virtually non-existent before the mid-20th century. This finding corresponds to previous studies on other European learned societies. Winkler-Dworak (2008) could not reveal a statistically significantly higher life expectancy for the members of the Austrian Academy of Sciences in comparison to the Austrian male population for the late 19th and early 20th century. Similarly, van de Kaa and de Roo (2008) did not find mortality differences between the members of the Royal Netherlands Academy of Arts and Sciences and the Dutch male population before the mid20th century. It was only the fellows of the Royal Society (Andreev et al. 2011) who exhibited a higher life expectancy at age 50 than the male population of England and Wales already in the 19th century. The lack of survival advantage of Austrian and Dutch 
academicians in the 19th century has been interpreted as a consequence of the predominately urban residence of academy members (Winkler-Dworak 2008) as well as being due to epidemics of infectious diseases (van de Kaa and de Roo 2008). The late 19th century in Germany was also characterised by increasing urbanisation and infectious diseases. Although mortality declined at the end of the 19th century due to medical and social progress and improvements in hygiene, this reduction was predominantly limited to childhood and early adult ages (Imhof 1994).

For the Saxonian Academy of Sciences, the development since the 1950s was characterised by an increasing difference in life expectancy between the academicians and the total population. Such a widening of the life expectancy differentials is documented for all analysed learned societies during that time, i.e. the Austrian Academy of Sciences (Winkler-Dworak 2008), the Royal Netherlands Academy of Arts and Sciences (van de Kaa and de Roo 2008) as well as the Royal Society and the Russian Academy of Sciences (Andreev et al. 2011). In general, widening social gaps in mortality in the second half of the 20th century have also been identified by other studies (e.g. Pamuk 1985; Marmot and McDowall 1986). In particular, Pamuk (1985) finds that the social gradient has been increasing in England and Wales since the 1950s, which is consistent with our findings.

There are two striking observations related to the increasing differences in survival between the SAW members and the general male population: first, the academicians were obviously insulated from the negative trends in life expectancy which occurred among German men in the 1950s and 1960s, quite similar to the Russian academicians who did not experience the mortality crisis among Russian men in the past decades either. Moreover, though there were differences in mortality between East and West German men, we do not find any statistically significant differences in survival between SAW members residing in East and West Germany. Hence, the results suggest that the survival of academicians is less determined by the general national mortality conditions.

Secondly, a decomposition of the differences in life expectancy at age 60 between SAW members and the total male population by age reveals that the academicians not only managed to make greater health improvement than the German male population at every age, but also that more than half of the difference is attributable to those aged 70 and above in the most recent period. Andreev et al. (2011) also found an increasing contribution of older ages to life expectancy differences between the members of the Royal Society and the Russian Academy of Sciences and the corresponding national population (although due to the increasing mortality of the Russian men at working age, the largest proportion of the mortality gap is in younger ages). Hence, our findings agree with Andreev et al. (2011, p. 324) that "differences in mortality at older ages have become more important in explaining the overall differences in longevity."

The discussion of the results has so far shown that the life expectancy of SAW members follows a similar trend as in other learned societies. Even more, the Saxonian academicians exhibited a life expectancy at age 60 of about 25.5 (23.1-28.2) years for the period 1996-2005, which is almost identical to corresponding values for the Austrian Academy of Sciences $(25.7,23.7-27.8)$ and the Royal Society $(25.4,24.5-26.3)$ for that period (Winkler-Dworak 2012). Only the Russian Academy members showed a slightly 
lower life expectancy at age 60 of 22.6 (21.6-23.5) years in 1996-2005. However, in the decades preceding that period the life expectancy values at age 60 were almost the same for the Saxonian and Russian academicians. Hence, there is even a close correspondence of life expectancy values over time among the members of the various academies, particularly in the past decades (Winkler-Dworak 2012). Indeed, academies of sciences, which comprise foreign and corresponding members, have always been international from their foundation, their members being globally active, with extensive personal and professional contact worldwide, particularly over the past half-century. As Andreev et al. (2011, p. 320) speculate " $[\mathrm{t}]$ his could have resulted in the global membership of these groups being early adopters of attitudes, behaviours, and lifestyles beneficial to health."

The longevity of European academicians is remarkable, in particular in the second half of the 20th century. The survival advantage of the academies is all the more striking as the past decades have been characterised by a strong increase in life expectancy for the European national populations, particularly for the older ages albeit, as mentioned in the beginning, not unexpected given the social gradient in mortality. The positive factors, e.g. high level of education and upper professional status associated with high income, accumulate for the academicians. Theories on the social differentials in mortality range from selection, material and structural explanations to cultural and behavioural approaches (for an overview see Townsend and Davidson 1982 and Valkonen 2001) and have extensively discussed for the case of academies of sciences in Andreev et al. (2011). For instance, a health-related selection effect may arise from their advanced age at election. A sensitivity analysis where the mortality experience of the first two, five, and eight years after election is excluded, and thus, producing an even more selected sample of academicians with respect to age, does not yield significantly different life expectancy estimates. However, the selection may also operate differently as it is likely to assume that only scientists who were particularly robust and not troubled by serious health problems in the first part of their adult life are likely to produce the outstanding scientific achievement which gets them elected to their academies (Andreev et al. 2011).

Material and structural approaches explain the mortality advantage of academicians and, more generally, of individuals with higher socio-economic status as they are usually less affected by health-damaging material living conditions and adverse working conditions than lower status groups. Andreev et al. (2011) further note that academicians may usually have experienced better-than-average socio-economic conditions in childhood and it has been shown that favourable socio-economic conditions during childhood reduce the risk of serious health problems in later life (Smith 2004).

According to cultural and behavioural explanations, the social mortality differentials are due to differences in the prevalence of risk behaviour such as smoking, alcohol abuse, lack of exercise, unhealthy dietary habits and, by contrast, the adoption of lifestyles which are beneficial to health but also access to, and use of, health services (Valkonen 2001). Moreover, there is evidence that people with higher educational levels are better at selfmanagement of diseases (Goldman and Smith 2002). Unfortunately, no information is available about the health-related behaviours of academy members in order to compare them to other social groups. However, if we cautiously interpret the small differences in survival among the SAW members by place of residence in East and West Germany, 
respectively, due to differences in medical care between East and West Germany before Reunification, we note that the survival differences started at later ages than those observed between the East and West German population at that time.

Other hypotheses for explaining the social mortality differentials in general relate to psycho-social factors, in particular to work-related psychological stress and autonomy and control at work as well as generally in life (Marmot 2004). The latter argument may indeed contribute to explaining the longevity of the academicians, as it is the advanced scientific career which is usually characterised by a high degree of autonomy, and the readiness and wish to stay active beyond retirement is more prevalent among scientists than in other professions. Kocka (2011, p. 14) further notes that many scientists even consider research and teaching activities as their mission or purpose in life. Indeed a learned society offers its members, particularly those who had to retire due to age reasons, the best possibilities for continued professional activities and social contacts (Kopetz 2006, p. 230). Academies of sciences not only serve their members by providing opportunities to carry on their research, they usually even oblige their members to engage in academy activities in their bye-laws. In fact, the productivity of older scientists in terms of publications has increased over the past decades (Stroebe 2010) which was possible because of the increasing life expectancy and better health of the academics (Weingart and Winterhager 2011). Or may we speculate even vice versa? Do academicians live longer because they remain active for longer times, even beyond retirement? One may regard as first evidence the increasing contribution of post-retirement ages to the observed life expectancy differentials between academicians and the general population. However, in order to fully explain the remarkable longevity of academicians, particularly in comparison to other social groups and the general population, more detailed data including life style, health-related behaviour and, most desirably, biomarkers are necessary. 


\section{References}

Andreev, E.M., V.M. Shkolnikov, and Alexandr. Z. Begun. 2002. Algorithm for decomposition of differences between aggregate demographic measures and its application to life expectancies, healthy life expectancies, parity progression ratios and total fertility rates. Demographic Research 7(14): 499-522.

Andreev, E.M., D. Jdanov, V.M. Shkolnikov, and D.A. Leon. 2011. Long-term trends in the longevity of scientific elites: Evidence from the British and the Russian academies of science. Population Studies 65(3): 319-334.

Dorbritz, J. and K. Gärtner. 1995. Bericht 1995 über die demographische Lage in Deutschland. Zeitschrift für Bevölkerungswissenschaft 20(4): 339-448.

Eberstadt, N. 1994. Demographic shocks after Communism: Eastern Germany, 1989-93. Population and Development Review 20: 137-152.

Gjonça, A., H. Brockmann, and H. Maier. 2000. Old-Age Mortality in Germany prior to and after Reunification. Demographic Research 3(1).

Goldman, D. and J. P. Smith. 2002. Can patient self-management help explain the SES health gradient? Proceedings of the National Academy of Sciences of the United States of America 99(16): 10929-10934.

Haudidier, B. 1996. Vergleich der Sterblichkeitsentwicklung in der Bundesrepublik Deutschland und in Frankreich 1950 bis 1989. In Sterblichkeitsentwicklung unter besonderer Berücksichtigung des Kohortenansatzes, ed. R. H. Dinkel, Ch. Höhn, and R. Scholz, 139-152, München: Boldt.

Horiuchi, S. 1983. The long-term impact on war on mortality. Old-age mortality of the First World War survivors in the Federal Republic of Germany. Population Bulletin of the United Nations 15: 80-92.

Houdaille, J. 1980. Mortalité dans divers groupes et notables du XVIIème au XIXème siècles. Population (4-5):966-968.

Human Life-Table Database. Max Planck Institute for Demographic Research (Germany), Department of Demography at the University of California, Berkeley (USA), and Institut national d'études démographiques (France) Available online at http://www.lifetable.de (data downloaded on 29.4.2009).

Human Mortality Database. University of California, Berkeley (USA) and Max Planck Institute for Demographic Research (Germany). Available at www.mortality.org or www.humanmortality.de (data downloaded on 19.8.2011).

Imhof, A. E., eds. 1994. Lebenserwartungen in Deutschland, Norwegen und Schweden im 19. und 20. Jahrhundert. Berlin: Akademie Verlag. 
Kaa, D. J. van de and Y. de Roo. 2008. De leden van de Koninklijke Nederlandse Akademie van Wetenschappen. Een demografisch perspectief: 1808 tot 2008. Amsterdam: KNAW Press.

Kaden, H., eds. 2009. Sächsische Akademie der Wissenschaften zu Leipzig. Jahrbuch 2007-2008. Stuttgart/Leipzig: S. Hirzel.

Kaden, H., eds. 2011. Sächsische Akademie der Wissenschaften zu Leipzig. Jahrbuch 2009-2010. Stuttgart/Leipzig: S. Hirzel.

Kaden, H., M. Winkler-Dworak, M., and E. Fischer. forthcoming. Eine demographische Studie zur Sächsischen Akademie der Wissenschaften zu Leipzig. Denkströme. Journal der Sächsischen Akademie der Wissenschaften, in press.

Kibele, E. and R. Scholz. 2009. Trend der Mortalitätsdifferenzen zwischen Ost und West unter Berücksichtigung der vermeidbaren Sterblichkeit. In Die Bevölkerung in Ost- und Westdeutschland Demografische, gesellschaftliche und wirtschaftliche Entwicklungen seit der Wende, ed. I. Cassens, M. Luy, R. Scholz, 124-139. Wiesbaden: VS Verlag für Sozialwissenschaften.

Kocka, J. 2011. Gewonnene Jahre für die Wissenschaft. In Das Alter (in) der Wissenschaft, ed. Berlin-Brandenburgische Akademie der Wissenschaften. Gegenworte: Hefte für den Disput über Wissen, vol. 25: 9-16.

Kopetz, H. 2006. Die Österreichische Akademie der Wissenschaften: Aufgaben, Rechtsstellung, Organisation. Wien: Böhlau

Lebenserwartung.info. Die Internetseiten mit vielfältigen Informationen zur Lebenserwartung in Deutschland von Marc Luy. Verfügbar unter www.lebenserwartung.info. (data downloaded on 30.3.2012).

Leridon, H. 2004. The demography of a learned society. The Académie de Sciences (Institut de France), 1666-2030. Population - E 59(1):81-114.

Leridon, H. 2005. The demography of a learned society. The Académie de Sciences (Institut de France), 1666-2030. Presentation given at the Workshop on "The Demography of Learned Societies", Vienna, November 30th, 2005.

Luy, M. 2004. Mortality differences between Western and Eastern Germany before and after Reunification. Genus, LX(3-4): 99-141.

Manton, K. G., E. Stallard, and H. D Tolley. 1991. Limits to human life expectancy: Evidence, prospects, and implications. Population and Development Review, 17(4): 603-637. 
Martelin, T. 1996. Socio-demographic differentials in mortality at older ages in Finland. In Health and mortality among elderly populations, ed. G. Caselli and A. D. Lopez, 112-134. Oxford: Clarendon Press.

Matthiessen, P. C. 1998. A demographic analysis of RDASL membership. In The joy of demography ... and other disciplines. Liber amicorum presented to Dirk van de Kaa on the occasion at this retirement as Professor at the University of Amsterdam, ed. A. Kuijsten, H. de Gans, H. and H. de Feijter, Amsterdam: Thela Thesis.

Marmot, M. 2004. Status Syndrome: How your social standing directly affects your health and life expectancy. London: Bloomsbury Publishing.

Marmot, M. G. and M. E. McDowall. 1986. Mortality decline and social inequalities. The Lancet 2(8501): 274-276.

Meyer, K. and G.-R. Rückert. 1975. Grippewellen und Sterblichkeitsentwicklung in Europa 1950-1970. Zeitschrift für Bevölkerungswissenschaft 1(3-4): 3-56.

Nolte, E., V. Shkolnikov, and M. McKee. 2000. Changing mortality pattern in East and West Germany and Poland: II. Short-term trends during transition and in the 1990s. Journal of Epidemiology and Community Health 54: 899-906.

Olshansky, S.J., B.A Carnes, and C. Cassel. 1990. In Search of Methuselah: Estimating the Upper Limits to Human Longevity. Science 250:634-640.

Pamuk, E. R. (1985) Social class inequality in mortality from 1921 to 1972 in England and Wales. Population Studies 39: 17-31.

Riphahn, R. T. 1999. Die Mortalitätskrise in Ostdeutschland und ihre Reflektion in der Todesursachenstatistik. Zeitschrift für Bevölkerungswissenschaft 24: 329-363.

StataCorp. 2009. Stata/SE 11.2. College Station, TX.

Schlegel, E., ed. 2007. Sächsische Akademie der Wissenschaften zu Leipzig. Jahrbuch 2005-2006. Stuttgart/Leipzig: S. Hirzel.

Shkolnikov, V.M., G.A. Cornia, D.A. Leon, F. Meslé. 1998. Causes of the Russian Mortality Crisis: Evidence and Interpretations. World Development 26(6): 1995-2011.

Smith, J. P. 2004. Unraveling the SES-health connection, Population and Development Review 30 (Suppl.: Aging, Health, and Public Policiy): 108-132.

Stroebe, W. 2010. The Graying of Academia: Will it Reduce Scientific Productivity. American Psychologist 65(7): 660-673.

Townsend, P. and N. Davidson. 1982. Inequalities in health: The Black Report. Harmondsworth, England: Penguin Books. 
Tukey, J. W. 1977. Exploratory Data Analysis. Reading, MA: Addison-Wesley.

Valkonen, T. 2001. Trends in socio-economic differences in mortality. In Trends in mortality and differential mortality, ed. J. Vallin, F. Meslé and T. Valkonen. Population Studies, no. 36. Strasbourg: Council of Europe Publishing.

Weingart, P. and M. Winterhager. 2011. Altern in und Altern der Wissenschaft. In "Das Altern (in) der Wissenschaft", ed. Berlin-Brandenburgische Akademie der Wissenschaften. Gegenworte: Hefte für den Disput über Wissen, vol. 25: 34-38.

Wiemers, G. and E. Fischer. 2006. Sächsische Akademie der Wissenschaften zu Leipzig. Die Mitglieder von 1846 bis 2006. 2nd enlarged and revised edition. Berlin: Akademie Verlag.

Winkler-Dworak, M. 2008. The Low Mortality of a Learned Society. European Journal of Population 24: 405-424.

Winkler-Dworak, M. 2012. The low mortality of learned societies: An international comparison". Presentation at the workshop "Determinants of Unusual and Differential Longevity", 21 Nov-23 Nov 2012. 


\section{VIENNA INSTITUTE OF DEMOGRAPHY}

\section{Working Papers}

Feichtinger, Gustav, Alexia Prskawetz, Andrea Seidl, Christa Simon and Stefan Wrzaczek, Do Egalitarian Societies Boost Fertility?, VID Working Paper 02/2013.

Muttarak, Raya, Is it (dis)Advantageous to Have Mixed Parentage? Exploring Education \& Work Characteristics of Children of Interethnic Unions in Britain?, VID Working Paper 01/2013.

Testa, Maria Rita and Stuart Basten, Have Lifetime Fertility Intentions Declined During the "Great Recession"?, VID Working Paper 09/2012.

Buber, Isabella, Ralina Panova, and Jürgen Dorbritz, Fertility Intentions of Highly Educated Men and Women and the Rush Hour of Life, VID Working Paper 08/2012.

Testa, Maria Rita, Laura Cavalli, and Alessandro Rosina, The Decision of Whether to Have a Child: Does Couple Disagreement Matter?, VID Working Paper 07/2012.

Kuhn, Michael and Klaus Prettner, Growth and Welfare Effects of Health Care in Knowledge Based Economies, VID Working Paper 06/2012.

Sander, Nikola and Martin Bell, Age, Period and Cohort Effects on Migration of the Baby Boomers in Australia, VID Working Paper 05/2012.

Grafeneder-Weissteiner, Theresa, Ingrid Kubin, Klaus Prettner, Alexia Prskawetz, and Stefan Wrzaczek, Coping with Inefficiencies in a New Economic Geography Model, VID Working Paper 04/2012.

Goujon, Anne, Éric Caron Malenfant, and Vegard Skirbekk, Towards a Catholic North America? Projections of Religion in Canada and the US beyond the Mid-21st Century, VID Working Paper 03/2012.

Di Giulio, Paola, Christoph Bühler, Andreas Ette, Romina Fraboni, and Kerstin Ruckdeschel, Social Capital and Fertility Intentions: The Case of Italy, Bulgaria, and West Germany, VID Working Paper 02/2012.

Abel, Guy J., Estimating Global Migration Flow Tables Using Place of Birth Data, VID Working Paper 01/2012.

Ediev, Dalkhat M., At Modal Age at Death, the Hazard Rate is Determined by its Derivative, VID Working Paper 08/2011.

The Vienna Institute of Demography Working Paper Series receives only limited review. Views or opinions expressed herein are entirely those of the authors. 